\title{
On the Thermal Insulation Qualification of Low Voltage Electrical Machines
}

\author{
Vincenzo Madonna ${ }^{1}$, Paolo Giangrande ${ }^{1}$, Giovanni Migliazza ${ }^{2}$, Giampaolo Buticchi ${ }^{1,3}$, \\ Michael Galea ${ }^{1,3}$ \\ ${ }^{1}$ PEMC Group, University of Nottingham, Nottingham, NG72RD, UK, Vincenzo.Madonna2@nottingham.ac.uk \\ ${ }^{2}$ Department of Science and Methods for Engineering, University of Modena and Reggio Emilia, Reggio Emilia, Italy \\ ${ }^{3}$ Key Laboratory of More Electric Aircraft Technology of Zhejiang Province, University of Nottingham Ningbo China, \\ Ningbo 315100, China
}

\begin{abstract}
Electrical motors are required to perform reliably for a certain number of hours/cycles. Assuming the insulation breakdown as the predominant source of failure, then the lifetime of an electrical machine can generally be said to correspond to that of its weakest insulation sub-system. Among all the insulation stressing factors, thermal aging is a primary source of progressive deterioration, and, eventually, failure. In order to guarantee a satisfactory lifetime, motors are designed to have thermal operational points which are always lower than their insulation thermal class. However, this design choice does not allow to maximize the exploitation of the insulation lifetime capability. Technical standards report methods for the thermal qualification of electrical machines based on accelerated thermal aging tests. Such assessment, despite enabling the insulation lifetime estimation, might require several thousand hours of testing. This paper, therefore, proposes and validates a new methodology which considerably shortens the thermal qualification of electric motors.
\end{abstract}

Index Terms-Design of experiments, Dielectric breakdown, Dielectric losses, Electric machines, Electric motors, Insulation, Physics of failure, Thermal factors, Thermal stresses

\section{INTRODUCTION}

I NSULATION breakdown is the main cause of stator failures in electrical machines (EMs) [1-3]. A number of aging stresses and influence factors can lead to the progressive deterioration of the insulation system in both low and high voltage EMs. The former, conventionally, adopt Type-I insulation, whose chemical composition features an organic nature $[4,5]$. Therefore, these machines are designed to be partial discharges (PD) -free throughout their lifetime [6,7]. Indeed, $\mathrm{PD}$, which are electrical discharges that only partially bridge the insulation between two electrical conductors, might cause the premature breakdown of organic insulating materials, if they are repetitively incepted [8-10]. Thus, for PD-free low voltage EMs, it is reasonable to assume thermal stress as the main source of insulation aging [11].

The thermal class of an EM is determined by its weakest insulation sub-system (i.e. the insulation sub-system with the lowest thermal class) [12]. For low voltage, random wound,

This work was funded by the INNOVATIVE doctoral programme. The INNOVATIVE programme is partially funded by the Marie Curie Initial Training Networks (ITN) action (project number 665468) and partially by the Institute for Aerospace Technology (IAT) at the University of Nottingham.

This work was also supported by the Natural Science Foundation of China with project code 51850410515 . This project has received funding from the Clean Sky 2 Joint Undertaking under the European Union's Horizon 2020 research and innovation programme under grant agreements no. 807081 and no. 821023 non-impregnated EMs, this is generally the magnet wire adopted for the windings. These wires are insulated by a thin enamel layer with organic chemical composition (e.g. polyamide, polyimide, polyester-imide etc...). Thus, for a given EM, if the windings lifetime (under stated operating conditions) is known, this corresponds to the lifetime of the whole EM. By 'lifetime' it is intended the number of hours/cycles, during which the EM operates with a failure probability below a certain threshold. This threshold can be set at the design stage, depending on the application. In fact, an EM for safety-critical applications, such as aerospace electromechanical actuators [13-19], must satisfy more stringent reliability constraints than EMs for e.g. home appliances.

Traditionally, at the EM design stage, the maximum hot-spot temperature that the insulation will experience throughout its lifetime is evaluated via thermal modelling techniques, such as lumped parameters thermal networks (LPTNs), computational fluid dynamic and finite element simulations [20-22]. The designer, then, acts on the EM design parameters so that the hot-spot temperature always remains below the thermal class of the adopted insulation [23, 24], which is provided by the insulating system manufacturer. This ensures that the EM will 'survive' at least 20,000 hours of continuous operation [25]. Although the aforementioned design philosophy works properly in the case of EMs intended for continuous duty, however it can reveal some limitations when short-time duty or periodic duty EMs are considered [26]. Indeed, if the EM insulation system is thermally sized based on the highest temperature experienced by the EM (i.e. insulation thermal class higher than the maximum winding temperature), the design would result in an over-engineered and expensive insulation (and a bigger/heavier machine). Thus, the insulation lifetime capability would not be properly exploited and the EM performance might not be optimized (e.g. low copper fill factor due to the thicker insulation). On the other hand, by choosing an insulation thermal class lower than the highest winding temperature, the EM will be exposed to the risk of premature aging. Considering this scenario, an appropriate knowledge of 1) the winding temperature profiles and 2) the insulation thermal endurance plot (i.e. insulation lifetime vs temperature) are demanded for improving the EM design. The former can be obtained through the EM thermal analysis (e.g. using LPTNs as mentioned above), whereas the latter can be determined according to the technical standards.

It is important to note, that technical standards suggesting methodologies for the thermal qualification of EMs do exist, and these allow for quite accurate estimations of the thermal lifetime at various operating temperatures [27]. However 
these qualification strategies require extensive testing, which can last thousands of hours [28].

In this paper, a new strategy for the thermal qualification of low voltage EMs is proposed. This is based on the Arrhenius law for chemical reactions, combined with the analysis of insulation degradation through the design of experiment approach. The validity of the introduced method is experimentally confirmed on custom designed EMs prototypes.

\section{THEORETICAL BACKGROUND}

The effect of temperature on EMs insulation lifetime has been studied since the 1930s, when V. M. Montsinger presented for the first time the ' 10 degrees rule', which states that the insulation lifetime is halved for every $10{ }^{\circ} \mathrm{C}$ temperature increment [29]. This empirical rule was partially confirmed in a paper published by Dakin in 1947 [30]. In this work, he demonstrates that the physical changes in insulating materials, subject to thermal aging, are the result of internal chemical reactions which obey the Arrhenius law. According to this law, the lifetime $L$ of a solid insulating material, in which temperature is the predominant stress factor, can be derived as in (1), where $\theta$ is the absolute temperature, while $A$ and $B$ are two constants, which depend on the material.

$$
L=A \cdot \exp (B / \theta)
$$

For a given insulation, by extrapolating the lifetime $L$ at three or more temperatures, it is possible to determine the Arrhenius curve (i.e. insulation lifetime vs. temperature). The latter is a straight line when reported on a semi-log plot, as can be seen in Fig. 1, where an example of Arrhenius curve for a class 180 insulating material is shown. From Fig. 1, the expected insulation lifetime for various temperatures can be obtained.

The accelerated aging tests need to be performed for drawing the Arrhenius plot [25, 31]. These consist in evaluating the material lifetime for (at least) three temperatures above the expected thermal class. For each of the selected temperatures, a number of specimens (generally 5 or more) are tested and their time to failure is recorded. In order to assess the specimen failure, an end-of-life criterion must be chosen [31]. A diagnostic property (or aging marker) $p$, intrinsic of the insulating material, can be then defined [32, 33]. The latter must change and follow a precise trend as the thermal aging accumulates [34]. If a specimen is aged at a generic temperature $\theta_{J}$, it will fail when $p$ equals $p_{L}$ (i.e. end-of-life criterion). The time necessary for $p$ to match $p_{L}$ (i.e. time to failure) corresponds to $L\left(\theta_{J}\right)$, as graphically illustrated in Fig. 2. Therefore, for the thermal qualification of an EM, a suitable diagnostic property $p$ and an end-of-life criterion have to be selected prior starting the accelerated aging tests. For Type-I insulated EMs that are rated at 300 Vrms (or above) and supplied by PWM converters, the end-of-life criterion is the inception of PD [35, 36]. The property $p$, in this case, is the repetitive partial discharge inception voltage (RPDIV). The latter, gradually decreases with thermal aging [37], and when it eventually reaches the limiting value (i.e. $p_{L}$ ), which will depend on the electric drive features (i.e. length of feeder cable and rise time of switching devices), the specimen is said to have failed.

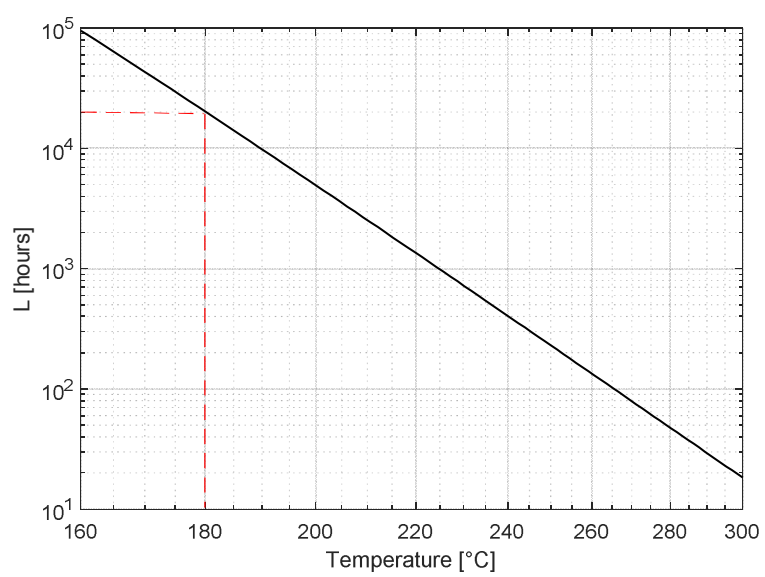

Fig. 1. Example of Arrhenius plot for a class 180 insulating material.

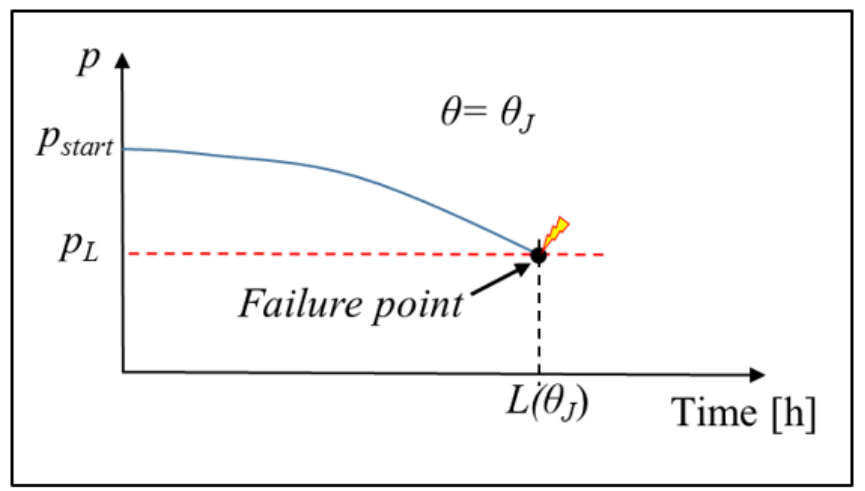

Fig. 2. End-of-life criterion definition for a generic insulation.

For EMs with rated voltage below 300 Vrms, a different diagnostic property needs to be considered, as these EMs are not expected to have PD inception at any point in time [9].

In this case, the most common aging marker is the dielectric strength, implying that the corresponding end-of-life criterion is the dielectric breakdown [38]. This can be detected through a hipot test, namely the application of a voltage whose amplitude is higher than that expected during normal service $[39,40]$.

Therefore, the qualification of an EM can be achieved through the following procedure:

1. Three temperatures above the (expected) insulation class must be firstly identified.

2. For each of these temperatures, a number of specimens must be aged until the insulation breakdown is detected.

3. The Arrhenius plot is determined through regression analysis (i.e. curve fitting) of the median (or other percentiles) of the failure times.

At this point, it is clear that if the chosen temperature is well above the thermal class, the time to breakdown [i.e. the testing (aging) time] will be relatively short. Nevertheless, for temperatures close to the thermal class, the testing time might be extremely long. As an example, assuming a material whose Arrhenius plot is the one reported in Fig. 1, and selecting a temperature of $200{ }^{\circ} \mathrm{C}$, the required aging time would be $\approx 5,000$ hours. In the following sections it will be demonstrated how this testing time can be considerably shortened. 


\section{THE PROPOSED PROCEDURE}

The generic aging marker $p$ introduced in Section II can be expressed as a function $f$ of time $t$ and temperature $\theta$ as shown in (2).

$$
p=f(t, \theta)
$$

When an insulation, stressed with a constant temperature $\theta_{J}$, reaches its end-of-life $L\left(\theta_{J}\right)$, the equality given by (3) must be satisfied.

$$
p_{L}=f\left[L\left(\theta_{J}\right), \theta_{J}\right]
$$

For electrical insulating materials, the common diagnostic markers are parameters such as the insulation resistance, dissipation factor (i.e. $\tan \delta$ ), insulation capacitance (IC), weight loss etc.

Once the function $f$ is mathematically defined for a single temperature $\theta_{l}$ (i.e. trend of the aging marker at $\theta_{l}$ ), then only a small number of 'long duration' aging cycles are required to predict the end-of-life at a temperature $\theta_{2}<\theta_{l}$ (i.e. longer aging test). These cycles are necessary to extrapolate the function $f$ for $\theta_{2}$. For clarity, the aforementioned procedure is graphically illustrated in Fig. 3. This approach reveals the following advantages: 1) only the aging test with shorter duration (i.e. at $\theta_{1}$ ) needs to be performed until the end-of-life is reached for all the specimens and 2) the longer aging tests (e.g. at $\theta_{2}$ and $\theta_{3}<\theta_{1}$ ) can be stopped earlier allowing a reduction of the whole test aging campaign

The diagnostic marker choice is crucial for the successful implementation of the proposed strategy. In 1986, G. C. Montanari analysed the thermal aging of Nomex-MylarNomex ${ }^{\circledR}$ composites [33] observing that the weight loss vs. thermal exposure time, is constant in a logarithmic plot. However, similar techniques have never been adopted for the study of low voltage EMs.

\section{CHOICE OF THE DiAgnostic MARKeR}

With the purpose of finding a suitable diagnostic marker $p$, a set of 5 motorettes has been manufactured and wound adopting a class 200 round enameled magnet wire with polyester-imide insulation. Each motorette has 3 coils composed by 2 subcoils and each subcoil features two strands. This allows to a) have a total of 6 subcoils (i.e. specimens) per motorette and b) asses the dielectric properties of the turn-to-turn insulation by performing measurements between strands. The unaged motorettes used for the experimental investigation are shown in Fig. 4.

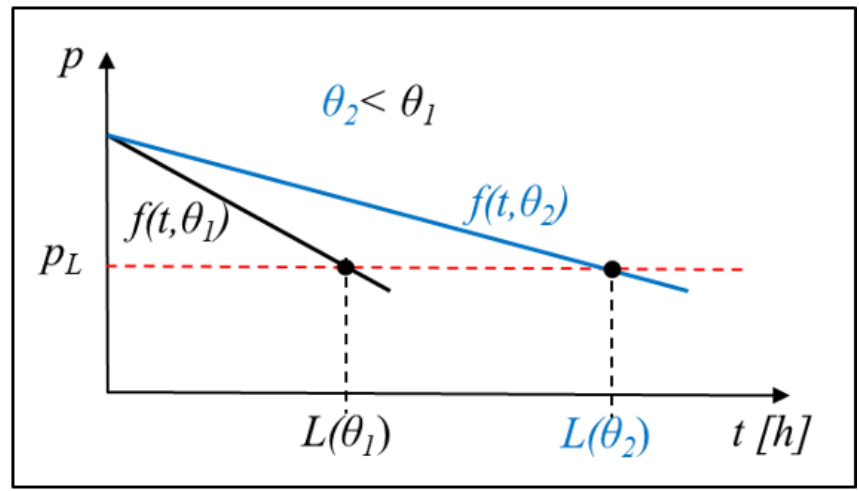

Fig. 3. Graphical explanation of the proposed thermal qualification procedure.

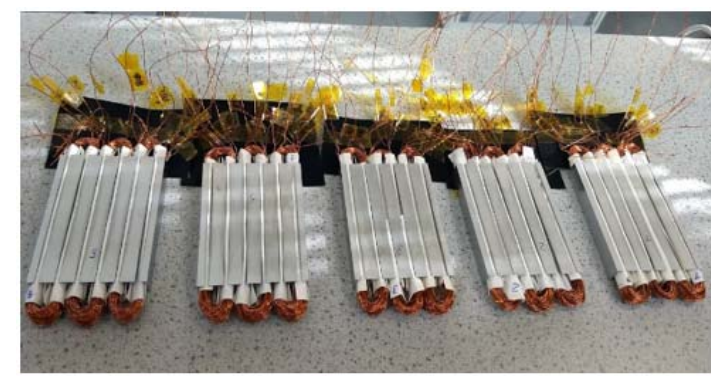

Fig. 4. Motorettes used during the thermal aging campaign.

The 30 specimens have been thermally aged in a ventilated oven with a constant temperature of $290^{\circ} \mathrm{C}$. Every 8 hours, of thermal exposure, the cooling time was awaited before removing the samples from the oven, and their turn-to-turn dielectric strength was assessed through the AC hipot test.

This test consists in ramping-up the $50 \mathrm{~Hz}$, sinusoidal voltage from 0 to $500 \mathrm{Vrms}$. When a specimen fails the AC hipot test, its time to failure is recorded. The aging campaign is carried out until the insulation breakdown is detected in all the specimens. At this point, the failure times are post-processed in order to analyse if they fit a statistical distribution. Fig. 5 reports the probability distribution plot of the failure times, from which it is possible to extract the median of the time to failure that is equal to $84 \mathrm{~h}$.

Two failure modes have been identified by the postprocessing of the failure times. With 33 hours of aging, the specimens' failure times fit a 3-parameter Weibull distribution, whilst from 33 hours up to the failure of the last specimen (i.e. $132 \mathrm{~h}$ ), they fit a 2-parameter Weibull distribution.

Throughout the accelerated aging cycles, a number of diagnostic markers have been monitored via a Megger ${ }^{\mathbb{B}}$ Delta 4000 to verify the existence of specific trends with the thermal aging. After post-processing the collected data via a custom built Matlab ${ }^{\circledR}$ script, it was observed that the specimens' strand-to-strand IC increased throughout the aging cycles.

A microscopy analysis of the aged coils revealed that the specimens' diameter decreased as a result of the thermal aging, as can be noted in the 10x enlargement shown in Fig. 6. Therefore, the IC increment with thermal aging can be attributed to the enamel thickness reduction as well as the variation of the enamel's relative dielectric constant (i.e. $\varepsilon_{r}$ ).

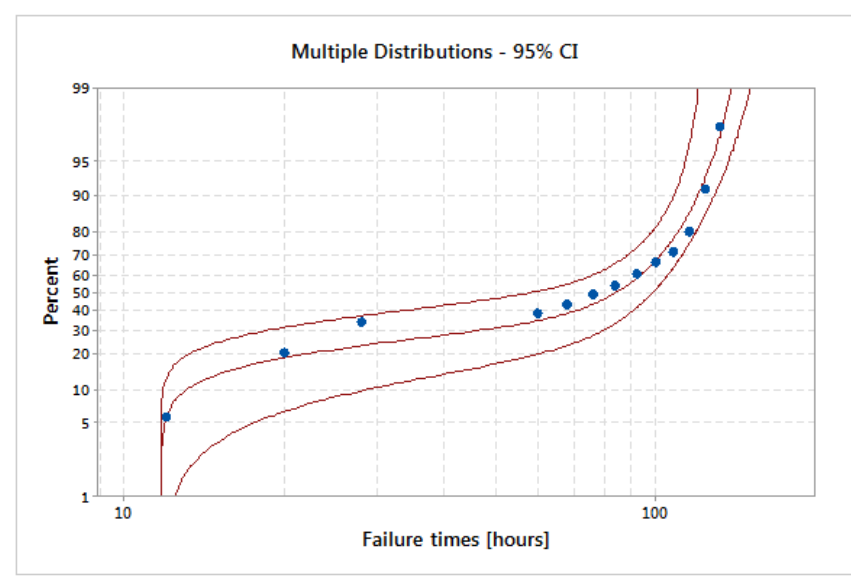

Fig. 5. Failure times probability plot with $95 \%$ confidence intervals for $290{ }^{\circ} \mathrm{C}$ aging temperature. 


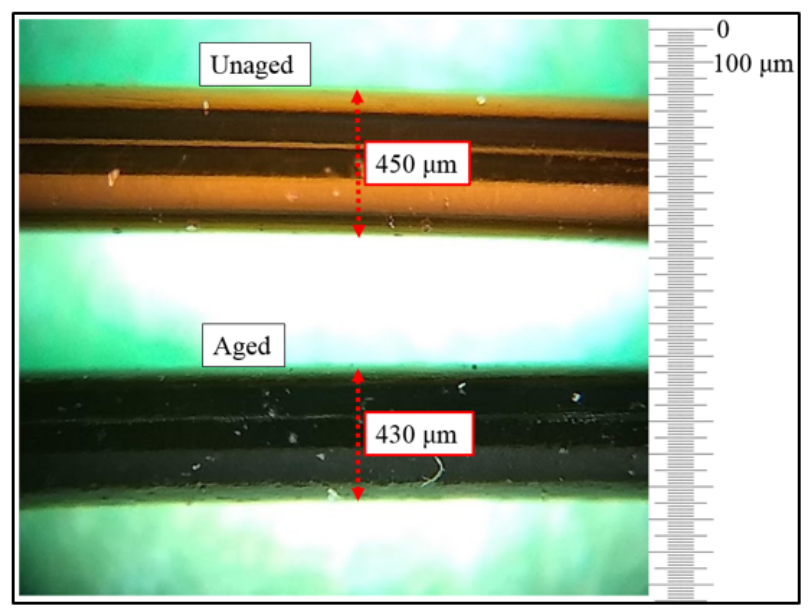

Fig. 6. Enamelled magnet wire thickness variation after 95 hours of thermal aging at $290{ }^{\circ} \mathrm{C}(10 \mathrm{x}$ magnification).

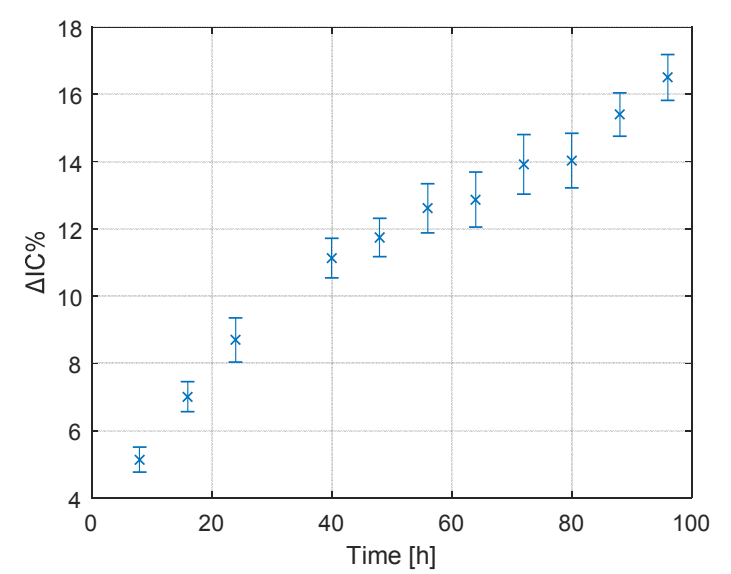

Fig. 7. Variation of $\Delta I C \%$ with thermal exposure at $290{ }^{\circ} \mathrm{C}$ in linear time scale.

From the post-processed data, a new quantity, here defined percent differential IC (i.e. $\triangle I C \%$ ), has been computed as indicated by (4), where $I C_{500}$ is the IC measured at $500 \mathrm{Vrms}$, while $I C_{100}$ is the IC measured at 100 Vrms.

$$
\Delta I C \%=100 \frac{I C_{500}-I C_{100}}{I C_{500}}
$$

The trend of $\triangle I C \%$ vs. thermal aging time at the constant temperature of $290{ }^{\circ} \mathrm{C}$ is reported in Fig. 7. By converting the time scale of Fig. 7 from linear to logarithmic, it was observed that $\triangle I C \%$ follows a linear trend (in logarithmic scale) with thermal aging as can be seen in Fig. 8. Consequently, the interpolating function $f$ of $\triangle I C \%$ [see (2)], can be written as in (5), where $q$ and $m$ are two curve fitting parameters and for $290{ }^{\circ} \mathrm{C}$, they are equal to -6.9 and 4.9 respectively.

$$
\Delta I C \%=q+m \cdot \log (t)
$$

This finding confirms that the $\triangle I C \%$ is a suitable diagnostic marker for insulation thermal aging.

It is important to note that for an aging time of $84 \mathrm{~h}$ at 290 ${ }^{\circ} \mathrm{C}$ [i.e. median of the failure times (see Fig. 5)], the $\triangle I C \%$ is equal to $14.8 \%$. The knowledge of this value is critical for the application of the proposed methodology, as it represents the $p_{L}$ parameter defined in (2) and illustrated in Figs. 2 and 3. For completeness, TABLE I summarizes all the quantities relative to the aging tests performed at $290{ }^{\circ} \mathrm{C}$.
TABLE I SUMMARY OF QUANTITIES RELATIVE TO $290^{\circ} \mathrm{C}$ TESTS

\begin{tabular}{cc}
\hline \hline Parameter & Value \\
\hline Median of failure times & $84 \mathrm{~h}$ \\
\hline$q$ of $(5)$ & -6.9 \\
\hline$m$ of $(5)$ & 4.9 \\
\hline$\Delta I C \%$ at failure & $14.8 \%$ \\
\hline \hline
\end{tabular}

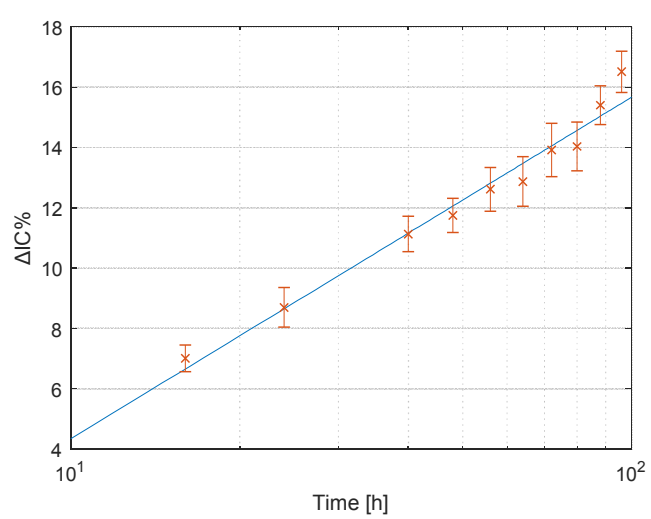

Fig. 8. Variation of $\Delta I C \%$ with thermal aging at $290{ }^{\circ} \mathrm{C}$ in logarithmic timescale and regression line (i.e. interpolating function $f$ ).

\section{APPLICATION AND VALIDATION}

Since a diagnostic marker has been found along with its interpolating function $f$, it is possible to use it to estimate the failure times' median of the tested specimens at temperatures different than $290^{\circ} \mathrm{C}$. For this purpose, the temperature of 270 ${ }^{\circ} \mathrm{C}$ has been chosen. Thus, a new set of specimens (i.e. subcoils wound around motorettes' teeth) featuring the same manufacturing properties (i.e. number of turns, number of strands, etc.) of the previous one, is aged at $270{ }^{\circ} \mathrm{C}$ following the procedure described in Section IV.

The thermal aging at $270{ }^{\circ} \mathrm{C}$ is intentionally stopped at 168 $\mathrm{h}$ (i.e. the test is not carried out until the failure of all specimen as prescribed by the standard procedure for EM thermal qualification) and the AC hipot test is performed every $24 \mathrm{~h}$. At this point, less than $15 \%$ of the specimens were found to have failed (i.e. 4 out of 30), hence, the adoption of standard thermal qualification procedures would not allow to evaluate the median of failure times. Thus, it can be said that the periodical measurement of the IC, throughout the aging cycles, enables the implementation of the proposed methodology.

Based on the recorded data during the aging test at $270{ }^{\circ} \mathrm{C}$, the $\triangle I C \%$ has been calculated according to (4). The trend of the $\triangle I C \%$ vs. aging time has been determined with the purpose of finding the parameters of the fitting curve given by (5). Indeed, these parameters for the aging temperature of 270 ${ }^{\circ} \mathrm{C}$ differ from the ones previously obtained at $290{ }^{\circ} \mathrm{C}$. The plot of $\triangle I C \%$ and its fitting (regression) line are reported in Fig. 9 on a logarithmic timescale. In this case (i.e. $270{ }^{\circ} \mathrm{C}$ ), $q$ and $m$ are equal to -27.4 and 7.5 respectively.

The estimated median of failure times for a temperature of $270{ }^{\circ} \mathrm{C} \mathrm{ttf} f_{270-e s t}$ can be calculated by rearranging (5) as in (6), and its value is equal to 278 hours.

$$
t t f_{270-e s t}=\exp \frac{14.8+27.4}{7.5}
$$

The same result can be achieved graphically by combining Figs. 8 and 9 on the same plot and applying the logical scheme of Fig. 3. This is shown in Fig. 10 where the temperatures vs. thermal aging interpolating curves (i.e. regression lines) for both $270{ }^{\circ} \mathrm{C}$ and $290^{\circ} \mathrm{C}$ are plotted. 


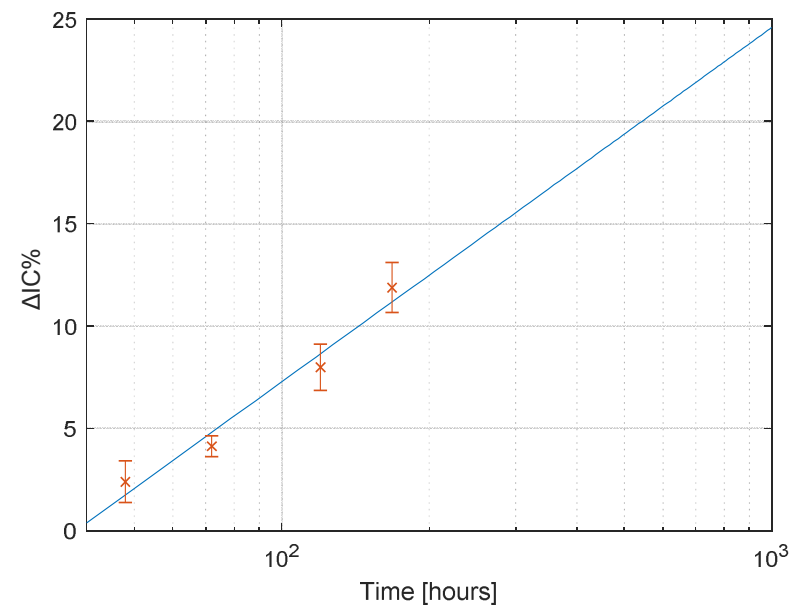

Fig. 9. Variation of $\Delta I C \%$ with thermal aging at $270{ }^{\circ} \mathrm{C}$ and regression line (i.e. interpolating function $f$ ).

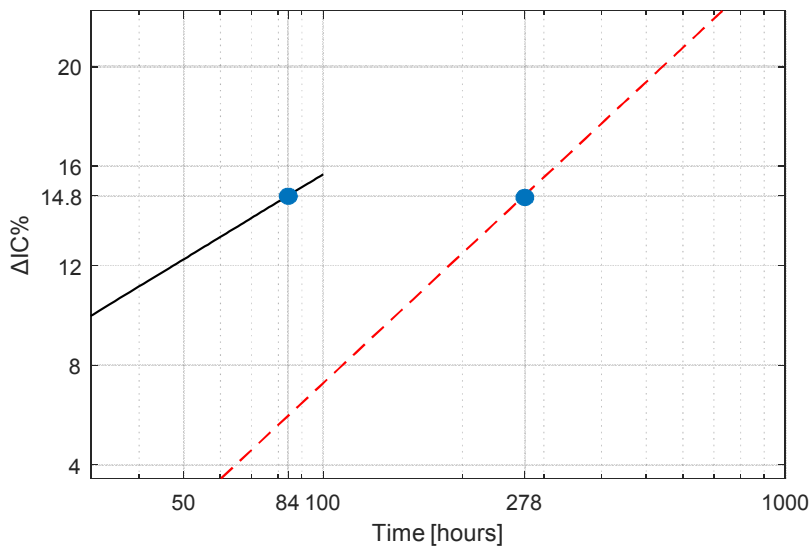

Fig. 10. Interpolating curves of $\triangle I C \%$ vs. aging hours for $290{ }^{\circ} \mathrm{C}$ (black continuous) and $270{ }^{\circ} \mathrm{C}$ (red dashed) temperatures.

In order to experimentally verify the accuracy of the proposed technique and confirm the estimated value of failure times' median (i.e. $t t f_{270-e s t}$ ), the thermal aging test at $270{ }^{\circ} \mathrm{C}$, that was previously stopped on purpose at $168 \mathrm{~h}$, was resumed and completed. In other words, the specimens (i.e. subcoils), which were already aged up to $168 \mathrm{~h}$ at $270{ }^{\circ} \mathrm{C}$, have been further thermally stressed until the insulation breakdown is induced in all the coils. The end-of-life criterion was kept unchanged and it is found to be the same as the one defined in Section IV for the specimens aged at $290{ }^{\circ} \mathrm{C}$ (i.e. AC hipot test). The experimentally collected failure times are summarized in Fig. 11, where the Weibull probability plot with $95 \%$ confidence intervals is shown.

From the Weibull probability plot, it is possible to extract the actual median of time to failure which is equal to $294.7 \mathrm{~h}$. Thus, it is easy to verify the good match between estimated and measured median time to failures, with a percent error lower than $6 \%$.

At this stage the benefit of the proposed methodology in terms of saved time is quite clear. The specimens' time to failure was predicted / achieved after only 168 hours of testing. A traditional strategy would have taken up to 432 hours to reach the point where all the specimen fail. From all this, an extra perceived advantage is that by applying the proposed technique to even lower temperatures (i.e. closer to the insulation thermal class), then the time-saved could be increased by an order of magnitude.

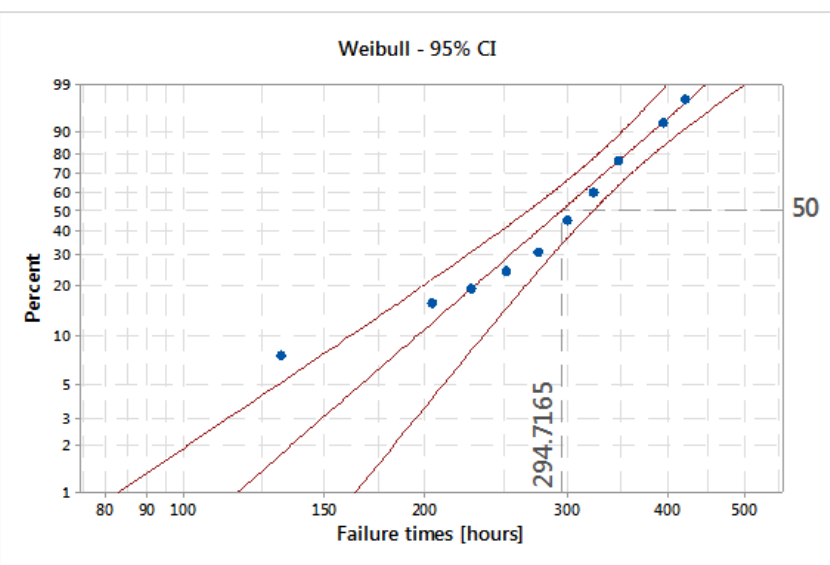

Fig. 11. Failure times probability plot with $95 \%$ confidence intervals for $270{ }^{\circ} \mathrm{C}$ aging temeprature.

\section{CONCLUSIONS}

As industry and transportation are moving towards more electrified solutions, faster thermal qualification and prototyping of electrical machines are becoming extremely important. Excellent advances have been made in the last two decades in terms of computationally efficient electromagnetic and thermal analysis of electrical motors. On the other hand, electrical machines lifetime modeling and prediction techniques have not yet achieved the same scientific interest. The reality, however, is that for safety-critical applications, reliability, lifetime evaluation and physics of failure are becoming essential requirements/objectives in electric motors design, and therefore these aspects cannot be considered as secondary objectives anymore.

In this paper a new methodology for fast thermal qualification of electrical machines insulation is proposed and experimentally validated. Its application allowed to save up to $60 \%$ of testing time (for lifetime) on a case-study prototype, guaranteeing an exceptional lifetime prediction accuracy.

By applying the proposed technique for the complete thermal qualification of an electrical machine, several thousands of testing hours can be saved, enabling extremely quick prototyping of newly designed motors. This makes the proposed method an ideal and easy-to-use tool for thermally qualifying a machine in a quick and accurate manner.

\section{REFERENCES}

[1] Y. Merizalde, L. Hernández-Callejo, and O. Duque-Perez, "State of the Art and Trends in the Monitoring, Detection and Diagnosis of Failures in Electric Induction Motors," Energies, vol. 10, p. 1056, 2017.

[2] S. Nandi, H. A. Toliyat, and X. Li, "Condition Monitoring and Fault Diagnosis of Electrical Motors-A Review," IEEE Transactions on Energy Conversion, vol. 20, pp. 719-729, 2005.

[3] P. Giangrande, A. Galassini, S. Papadopoulos, A. Al-Timimy, G. L. Calzo, M. Degano, et al., "Considerations on the Development of an Electric Drive for a Secondary Flight Control Electromechanical Actuator," IEEE Transactions on Industry Applications, vol. 55, pp. $3544-3554,2019$.

[4] V. Madonna, P. Giangrande, W. Zhao, G. Buticchi, H. Zhang, C. Gerada, et al., "Reliability vs. Performances of Electrical Machines: Partial Discharges Issue," presented at the IEEE WEMDCD'19 Workshop on Electrical Machines Design, Control and Diagnosis, Athens, Greece, 2019.

[5] A. Cavallini, "Reliability of low voltage inverter-fed motors: What have we learned, perspectives, open points," in 2017 International Symposium on Electrical Insulating Materials (ISEIM), 2017, pp. 1322. 
[6] V. Madonna, P. Giangrande, W. Zhao, Y. Wang, H. Zhang, and M. Galea, "Insulation Capacitance as Diagnostic Marker for Thermally Aged, Low Voltage Electrical Machines," presented at the 2019 22nd International Conference on Electrical Machines and Systems (ICEMS), Harbin, 2019.

[7] L. Lusuardi, A. Cavallini, M. G. d. 1. Calle, J. M. Martínez-Tarifa, and G. Robles, "Insulation design of low voltage electrical motors fed by PWM inverters," IEEE Electrical Insulation Magazine, vol. 35, pp. 7$15,2019$.

[8] P. Wang, G. C. Montanari, and A. Cavallini, "Partial Discharge Phenomenology and Induced Aging Behavior in Rotating Machines Controlled by Power Electronics," IEEE Transactions on Industrial Electronics, vol. 61, pp. 7105-7112, 2014.

[9] V. Madonna, P. Giangrande, W. Zhao, H. Zhang, C. Gerada, and M. Galea, "On the Design of Partial Discharge-Free Low Voltage Electrical Machines," presented at the IEMDC 2019 - International Electric Machines \& Drives Conference, 2019.

[10] D. Fabiani, "Accelerated degradation of ac-motor winding insulation due to voltage waveforms generated by adjustable speed drives," $\mathrm{PhD}$, University of Bologna, Bologna, Italy, 2003.

[11] V. Madonna, P. Giangrande, L. Lusuardi, A. Cavallini, C. Gerada, and M. Galea, "Thermal overload and insulation aging of short duty cycle, aerospace motors," in press on IEEE transactions on Industrial Electronics, 2019.

[12] "IEC 60505:2011 Evaluation and qualification of electrical insulation systems," ed: IEC, 2011.

[13] P. Giangrande, V. Madonna, S. Nuzzo, and M. Galea, "Design of FaultTolerant Dual Three-Phase Winding PMSM for Helicopter Landing Gear EMA," presented at the 2018 IEEE ESARS-ITEC, Nottingham UK, 2018.

[14] G. Buticchi, S. Bozhko, M. Liserre, P. Wheeler, and K. Al-Haddad, "On-board Microgrids for the More Electric Aircraft - Technology Review," IEEE Transactions on Industrial Electronics, pp. 1-1, 2018.

[15] W. Cao, B. C. Mecrow, G. J. Atkinson, J. W. Bennett, and D. J. Atkinson, "Overview of Electric Motor Technologies Used for More Electric Aircraft (MEA)," IEEE Transactions on Industrial Electronics, vol. 59, pp. 3523-3531, 2012.

[16] P. Giangrande, V. Madonna, G. Sala, A. Kladas, C. Gerada, and M. Galea, "Design and Testing of PMSM for Aerospace EMA Applications," in IECON 2018 - 44th Annual Conference of the IEEE Industrial Electronics Society, 2018, pp. 2038-2043.

[17] J. W. Bennett, B. C. Mecrow, D. J. Atkinson, and G. J. Atkinson, "Safety-critical design of electromechanical actuation systems in commercial aircraft," IET Electric Power Applications, vol. 5, pp. 37$47,2011$.

[18] V. Madonna, P. Giangrande, C. Gerada, and M. Galea, "Thermal analysis of fault-tolerant electrical machines for aerospace actuators," IET Electric Power Applications, vol. 13, pp. 843-852, 2019.

[19] M. Lukic, A. Hebala, P. Giangrande, C. Klumpner, S. Nuzzo, G. Chen, et al., "State of the Art of Electric Taxiing Systems," in 2018 IEEE ESARS-ITEC, 2018, pp. 1-6.

[20] M. Popescu, D. A. Staton, A. Boglietti, A. Cavagnino, D. Hawkins, and J. Goss, "Modern Heat Extraction Systems for Power Traction Machines - A Review," IEEE Transactions on Industry Applications, vol. 52, pp. 2167-2175, 2016.

[21] V. Madonna, A. Walker, P. Giangrande, G. Serra, C. Gerada, and M. Galea, "Improved Thermal Management and Analysis for Stator EndWindings of Electrical Machines," IEEE Transactions on Industrial Electronics, vol. 66, pp. 5057-5069, 2019.

[22] A. Boglietti, A. Cavagnino, D. Staton, M. Shanel, M. Mueller, and C. Mejuto, "Evolution and Modern Approaches for Thermal Analysis of Electrical Machines," IEEE Transactions on Industrial Electronics, vol. 56, pp. 871-882, 2009.
[23] V. Madonna, P. Giangrande, A. Walker, and M. Galea, "On the Effects of Advanced End-Winding Cooling on the Design and Performance of Electrical Machines," in 2018 XIII International Conference on Electrical Machines (ICEM), 2018, pp. 311-317.

[24] P. Lindh, I. Petrov, A. Jaatinen-Värri, A. Grönman, M. MartinezIturralde, M. Satrústegui, et al., "Direct Liquid Cooling Method Verified With an Axial-Flux Permanent-Magnet Traction Machine Prototype," IEEE Transactions on Industrial Electronics, vol. 64, pp. 6086-6095, 2017.

[25] "IEC 60172:2015 Test procedure for the determination of the temperature index of enamelled and tape wrapped winding wires," ed: IEC, 2015.

[26] V. Madonna, P. Giangrande, L. Lusuardi, A. Cavallini, and M. Galea, "Impact of thermal overload on the insulation aging in short duty cycle motors for aerospace," in 2018 IEEE ESARS-ITEC, 2018, pp. 1-6.

[27] "IEEE Standard Test Procedure for Thermal Evaluation of Systems of Insulating Materials for Random-Wound AC Electric Machinery," IEEE Std 117-2015 (Revision of IEEE Std 117-1974), pp. 1-34, 2016.

[28] P. Mancinelli, S. Stagnitta, and A. Cavallini, "Qualification of Hairpin Motors Insulation for Automotive Applications," IEEE Transactions on Industry Applications, vol. 53, pp. 3110-3118, 2017.

[29] V. M. Montsinger, "Loading Transformers By Temperature," Transactions of the American Institute of Electrical Engineers, vol. 49, pp. 776-790, 1930.

[30] T. W. Dakin, "Electrical Insulation Deterioration Treated as a Chemical Rate Phenomenon," Transactions of the American Institute of Electrical Engineers, vol. 67, pp. 113-122, 1948.

[31] "IEC 60034 18-21: Functional evaluation of insulation systems - Test procedures for wire-wound windings - Thermal Evaluation and classification," ed, 2012.

[32] G. C. Montanari and L. Simoni, "Aging phenomenology and modeling," IEEE Transactions on Electrical Insulation, vol. 28, pp. 755-776, 1993.

[33] G. C. Montanari and G. Pattini, "Thermal Endurance Evaluation of Insulating Materials: A Theoretical and Experimental Analysis," IEEE Transactions on Electrical Insulation, vol. EI-21, pp. 69-77, 1986.

[34] V. Madonna, P. Giangrande, and M. Galea, "Evaluation of Strand-to-Strand Capacitance and Dissipation Factor in Thermally Aged Enameled Coils for Low voltage Electrical Machines," IET Science, Measurement \& Technology, 2019.

[35] A. M. E.-. Refaie, J. P. Alexander, S. Galioto, P. B. Reddy, K. K. Huh, P. d. Bock, et al., "Advanced High-Power-Density Interior Permanent Magnet Motor for Traction Applications," IEEE Transactions on Industry Applications, vol. 50, pp. 3235-3248, 2014.

[36] L. Lusuardi, A. Cavallini, P. Mancinelli, G. D. L. C. Manuel, J. M. Martínez-Tarifa, and G. Robles, "Design criteria for inverter-fed Type 1 motors," in 2016 IEEE International Conference on Dielectrics (ICD), 2016, pp. 605-608.

[37] S. Savin, S. Ait-Amar, and D. Roger, "Turn-to-turn capacitance variations correlated to PDIV for AC motors monitoring," IEEE Transactions on Dielectrics and Electrical Insulation, vol. 20, pp. 3441, 2013.

[38] V. Madonna, P. Giangrande, and M. Galea, "Introducing Physics of Failure Considerations in the Electrical Machines Design," presented at the IEMDC 2019 - International Electric Machines \& Drives Conference, 2019.

[39] G. C. Stone, I. Culbert, E. A. Boulter, and H. Dhirani, Electrical Insulation for Rotating Machines: Design, Evaluation, Aging, Testing, and Repair: Wiley, 2014.

[40] S. Grubic, J. M. Aller, B. Lu, and T. G. Habetler, "A Survey on Testing and Monitoring Methods for Stator Insulation Systems of Low-Voltage Induction Machines Focusing on Turn Insulation Problems," IEEE Transactions on Industrial Electronics, vol. 55, pp. 4127-4136, 2008. 